\title{
AOR
}

Selected Papers of \#AolR2019:

The $20^{\text {th }}$ Annual Conference of the Association of Internet Researchers Brisbane, Australia / 2-5 October 2019

\section{GENDERED LIVED EXPERIENCE OF DIGITAL INCLUSION IN RURAL AUSTRALIA}

Amber Marshall

Digital Media Research Centre, QUT

\section{Introduction}

Digital inclusion is becoming an important topic of debate in Australia amongst academics, policy makers and practitioners. The Australian Digital Inclusion Index (ADII) measures digital inclusion along three indices: access, affordability, and digital ability. Based on an annual national survey of 50,000 people, the ADII compiles numerous variables into a score ranging from 0 to 100. A 'perfectly included' individual scores 100 and the average Australian scores 60.2 (Thomas et al., 2018).

Digital inclusion is intertwined with social inclusion in two ways. First, social disadvantage based on geography, gender, race, income, education and other factors is an antecedent to digital exclusion. Second, digital exclusion can compound social exclusion. In Australia, remoteness is a strong indicator of digital exclusion (Park, 2017, p. 399). In 2018, rural Australians scored 53.9 on the ADIl compared to 62.4 in capital cities. This 'city-country divide' is well-documented and is widening.

\section{Research approach}

The research was undertaken in one of Australia's most digitally excluded regions North West Queensland (NWQ), which had an ADII score of 52.8 in 2018 and just 45.9 in 2017. Specifically, the research investigated access, affordability and digital ability amongst agricultural households in the Northern Gulf region. While this project aimed to demonstrate how digital connectivity (or lack thereof) enables and constrains businesses and lives for farmers, it did not address the specific but equally pressing challenges for NWQ's Indigenous communities and people working in other industries (e.g. tourism, health, education, police). The farming focus is in response to unpublished ADII data (Thomas et al., 2017) suggesting that 'farmers and farm workers' return lower digital inclusion scores than other populations in rural areas.

Between May and October 2018, the researcher shadowed a Northern Gulf Drought Ambassador to talk to farmers about the reality of internet and telecommunications Suggested Citation: Marshall, A. H. (2019, October 2-5). Gendered lived experience of digital inclusion in rural Australia. Paper presented at AolR 2019: The $20^{\text {th }}$ Annual Conference of the Association of Internet Researchers. Brisbane, Australia: AolR. Retrieved from http://spir.aoir.org. 
connections, and how digital technologies are (or aren't) used for business, education and civic participation. Data were collected through ethnographic interviews/focus groups and participant observations at rural events and property visits. In addition, three case studies of farming households were undertaken to dive deeper into emerging issues. Thematic analysis based on the three pillars of digital inclusion revealed the following findings.

\section{Findings}

The research highlighted several unique challenges and opportunities for rural, farming women in particular to get connected and improve their lives through digital participation, which were manifest in several ways.

\section{Reinforcement of gender roles}

The research revealed that traditional western gender roles in some rural households both enabled and constrained digital access and ability for women. Some 'patriarchs' property owners who often direct business and domestic spending - showed little interest in using or investing in digital technologies. For these patriarchs, who have spent most of their lives in the paddock, it can be difficult to grasp why digital connectivity is necessary or even desirable. There can also be a preference for 'tried and true' farming equipment and practices and consequent distrust in digital technologies. One contributing factor is that many of these men had little opportunity to go to school, and therefore have poor general literacy, further inhibiting digitally literacy. It is therefore often easier for patriarchs to ask other family members - such and their wife or children - to complete essential tasks online on their behalf, such as answering emails. Accordingly, there is often a perception that computer work is women's work. Ironically, the research found that, through obligatory exposure to computer work, rural women develop digital skills such as banking and bookkeeping.

\section{Management of scarce digital resources}

The research found that many women manage and allocate available household resources, including consumables like internet data. Unlike internet plans in urban areas, on-peak data is capped for rural customers on NBN Sky Muster satellite plans, which forces many users to log on during off-peak times (e.g.12 midnight to 7 am). Also, where rural consumers rely on $3 / 4 \mathrm{G}$ mobile broadband, the network is often very congested, delivering download/upload speeds of only a few megabits per second.

When internet access and data is scarce, the research showed that women tend to put others' needs ahead of their own. For example, children's education (e.g. distance learning via data-hungry video) understandably comes first, and business activities (such as banking, payroll and online accreditation) take precedence over a women's online personal or professional development. Even the digital needs of farm workers are often prioritised because it is increasingly essential to offer wi-fi to attract and retain young and competent staff.

Under such circumstances, women devise elaborate ways to allocate and track use of data. One mother of two said she allocates specific amounts of data to the farm 
business, kids' education and parents' interests, and then allows her kids to "go nuts" on YouTube on the seventh day of every month before the new cycle begins (if there is any data left). The general attitude of women towards this data scarcity was that they just 'get on with it'. Living on the land, many resources are scarce (fuel, food, water) and data is just another resource to be managed fugally.

\section{Thirst for digital skills}

Rural farming women - who are already geographically isolated - suffer greater levels of social exclusion owing to lack of access to digital technologies. Despite this, the research revealed many women have a thirst for connections and opportunities afforded digital connectivity. The need for digital skills development was evident in a 'Bush Business' program where farming women reported gaining life-changing digital knowledge to start or expand their own businesses. These women also stay connected on Facebook across many hundreds of kilometres and many months between physical meetings.

\section{Conclusion}

This research investigated the lived experience of digital inclusion in rural farming populations in NWQ. While the ADII provides a year-on-year indicator of overall digital inclusion, this research sought to understand the localised factors that impact people's access to affordable internet and their capacity use it. The findings give insight into the role gender plays in compounding low levels of digital incision in rural farming households. Specifically, it reveals a paradox in women's lived experience of digital inclusion. While some women have limited control over investment in digital technologies, they are thrust into taking responsibility for managing digital resources and undertaking digital work, which ironically empowers them with digital skills and connections. This taste for digital participation spurs them to seek out further opportunities afforded by digital technologies, such as starting their own business. There is virtually no support for women (or men) to develop digital ability in the NWQ context. Investment in digital ability programs in rural Australia is crucial to prevent farmers and other rural populations being left behind in today's fast-paced digital economy.

\section{References}

Park, S. (2017). Digital inequalities in rural Australia: A double jeopardy of remoteness and social exclusion. Journal of Rural Studies. (54), 399-407.

Thomas, J., Barraket, J., Wilson, C.K., Cook, K., Louie, Y., Holcombe-James, I., Ewing, S., \& MacDonald, T. (2018). Measuring Australia's Digital Divide: The Australian Digital Inclusion Index 2018. Melbourne: RMIT University, for Telstra.

Thomas, J., Barraket, J., Wilson, C.K., Ewing, S., MacDonald, T., Tucker, J. \& Rennie, E., (2017). Measuring Australia's Digital Divide: The Australian Digital Inclusion Index, 2017, RMIT University, Melbourne, for Telstra. 